\title{
Naturalistic Driving Patterns of Older Adults Before and After Cataract Surgery
}

\author{
Michelle M. Porter, PhD ${ }^{1,2}$, Andrew W. Cull, BSc. ${ }^{1,2}$ \\ ${ }^{1}$ Faculty of Kinesiology and Recreation Management, and ${ }^{2}$ Centre on Aging, University of \\ Manitoba, Winnipeg, MB, Canada
}

Corresponding author contact information:

Michelle M. Porter, Ph.D., Director

Centre on Aging

338 Isbister Building

University of Manitoba

Winnipeg, MB

Canada

R3T 2N2

2044748795 (phone)

2044747576 (fax)

michelle.porter@umanitoba.ca

DOI: $10.1016 /$ j.jcjo.2017.12.016

https://www.sciencedirect.com/science/article/abs/pii/S0008418217307354

Running title: $\quad$ Driving patterns before and after cataract surgery 


\section{ABSTRACT}

Background. Cataract surgery can have many benefits for older adults, including enabling continued driving. However, it is not known how objectively measured driving patterns change after cataract surgery. Objective. The purpose of this study was to examine how participants from the Winnipeg site of Candrive (a longitudinal study of older drivers in Canada) drove before and after cataract surgery. Methods. An in-vehicle device monitored all trips taken at 1 second intervals allowing for the analysis of distances driven, number of trips, time of trips, speeding, excessive braking/accelerating, as well as the types of roadways. Hypotheses. It was hypothesized that after cataract surgery participants would drive further. Secondarily it was also hypothesized that participants would make more trips, drive further from home on different roadway types, drive in the dark more, speed more, and have fewer episodes of hard brakes and accelerations. Results. Over the four years of data collection, there were 16 cases of participants having cataract surgery, whereby there was also suitable driving data for analyses. Participants drove $28 \%$ further distances after surgery $(\mathrm{p}=0.022)$. They also had drove further from home, more on primary roads ( $\mathrm{p}<0.05)$, and had fewer episodes of hard braking per distance travelled $(\mathrm{p}<0.001)$. No other variables significantly changed. Conclusions. This study suggests that older drivers changed some of their driving patterns after cataract surgery. Future studies could explore the effects of increased driving exposure, in conjunction with potentially safer driving behaviors, on overall driving safety after cataract surgery.

Keywords: Aging, automobile driving, cataract surgery, GIS, mobility 
Cataract surgery has many benefits for older adults. One possible benefit is a decreased crash risk when driving ${ }^{1,2,3}$. What is not clear from the literature is how driving patterns change after an older driver has cataract surgery. This is important to know because driving patterns can affect crash risk ${ }^{4}$. In studies examining cataract surgery and crash risk, exposure for individual participants has either been based on proxy self-reported values ${ }^{3}$ or self-reports of participants ${ }^{2}$. However, self-reported information on distance driven has been shown to be inaccurate for many older drivers when compared to objectively measured distances ${ }^{5,6,7}$.

The purpose of this study was to examine whether driving patterns were different before and after cataract surgery in older drivers, as measured objectively by an in-vehicle device. It was hypothesized that after cataract surgery participants would drive further. Secondarily, it was also hypothesized that participants would make more trips, travel further from home, drive more in the dark, venture onto larger roadways, speed more, and have fewer episodes of hard brakes and accelerations.

\section{METHODS}

\section{Study Participants}

Participants were from the Winnipeg site of Candrive (a longitudinal study of older drivers in

Canada) ${ }^{8}$. This study was approved by the University of Manitoba Education and Nursing Research Ethics Board, and all participants provided written informed consent. Inclusion criteria for the main study included: regular driving (4 times per week), and 70 years and older. For the Winnipeg site, enrollment began in August 2009 and finished in September 2010. Participants were followed until September 2013. In order to be included in these analyses, participants had 
to report having cataract surgery during the study, and have valid driving data both before and after the surgery.

\section{Equipment and data analysis}

An in-vehicle device (OttoView-CD Autonomous Data Logging Device (Otto) (Persen

Technologies, Winnipeg, MB, Canada) monitored all trips taken using GPS and in-vehicle data. This allowed for the analysis of: 1) distances driven, 2) number of trips, 3) distance driven in the dark, 5) proportion of time exceeding speed limits, 6) excessive braking and accelerating, and 7) types of roadways used. With this device a trip goes from ignition on until ignition off. See Porter et al. for more details on the device ${ }^{7}$.

In order to classify a trip as occurring in the dark, GPS coordinates and date/time were used to determine sunset and sunrise times ${ }^{9}$. Speeding was assessed at different speed limits (50 to 110 $\mathrm{km} / \mathrm{hr}$ ), although many individuals did not drive on roadways with higher speed limits, during the time period under investigation, and so 50, 60 and $70 \mathrm{~km} / \mathrm{hr}$ speed limits only were analyzed statistically. Excessive acceleration and braking were analyzed using a threshold of $\geq$ $0.27369795918 \mathrm{~g}$ or $\leq-0.27369795918 \mathrm{~g}^{10}$, per distance or number of stops. The latter could be a more valid indication of hard braking or accelerating behaviour, because the type of roadway and its number of intersections would affect the number of times that someone would need to stop, and so excessive accelerations/ per distance travelled could be confounded by the type of roadway.

In these analyses, we categorized the roadway types by using the key for highways of Open Street Map Wiki ${ }^{11}$. We combined motorway and trunk, because only small parts of roadways in 
Manitoba were categorized as motorway. We also combined residential, tertiary and unclassified as these roadways had similar characteristics. We did not analyze link and service roadways because the amount these were used was very small. This resulted in four different road type categories: primary, secondary, residential and trunk. For one participant who moved during this time period, we did not examine distance from home.

Data were statistically analysed using paired t-tests and Wilcoxon signed rank tests, as applicable. In addition, 2 way repeated measures ANOVAs were performed for speeding as well road type analyses, with speed limit or road type as factors for each, respectively.

\section{RESULTS}

Over the four years of data collection (2009 to 2013), there were 16 cases of participants (11 men and 1 woman) having cataract surgery, whereby there were also suitable driving data for analyses. The participants ranged in age from 73 to 89 years $(80.3 \pm 5.2)$.

The median number of weeks examined before and after surgery was 11.5 and 11.0 respectively, which was not significantly different.

There were several significant changes in driving patterns after surgery (see Table 1 for details). For the main hypothesis, participants drove 28\% further (on average) after surgery. Figure 1 shows individual level changes for all cases, with only 3 cases having decreases. There were also significant changes in trips that took them further from home, increased distances travelled on primary roadways, and also there were fewer episodes of hard braking per distance travelled. 
There were no significant changes in the number of trips, night driving, speeding at any speed limit, excessive acceleration, or number of hard brakes per stop.

\section{DISCUSSION}

This study suggests that older drivers changed some of their driving patterns after cataract surgery. Most importantly, as hypothesized, these participants drove further. The reason for the changes in measured driving patterns are not clear from this study. It could be that vision improvements were directly linked to driving behaviours, but this could not be assessed using this design, as vision tests were not done at the time of the objective measurements of driving patterns. It is also possible that it was not directly linked to vision improvements, but instead it was linked to perceptions of improved visual ability. MacDonald et al. ${ }^{12}$ found that perceived abilities were more linked to driving patterns than objective performance.

Previous studies that have examined older drivers after cataract surgery have found that participants self-reported less difficulty in estimating distance while driving ${ }^{13}$, and that visual acuity and contrast sensitivity were improved ${ }^{14}$. The latter study also demonstrated that improvements in visual performance were positively related to driving performance ${ }^{14}$. These driving-related improvements included: sign recognition, ability to detect and avoid hazards, and overall driving score ${ }^{14}$. Although the study by Wood and Carberry ${ }^{14}$ did not examine crash data, other studies have shown that crash rates go down after cataract surgery ${ }^{1,2,3}$.

As mentioned above, crash rates have been shown to decline in those who have had cataract surgery $^{1,2,3}$, although it is not clear what the objective driving exposure was for the participants examined. If older drivers drive more following surgery, this suggests that their risk for 
crashing should be increased because their overall exposure is increased. However, if their crash risk does in fact go down, even in the face of increased exposure, this implies that older drivers become particularly safe after cataract surgery. Alternatively, their driving patterns could decrease their risk of crashes because of the types of roadways that they drive on. It has been posited in the low mileage bias theory, that driving close to home, in residential areas, effectively increases the risk of crashing because there are more opportunities for conflicts ${ }^{3}$. In the participants studied here, after they had cataract surgery, they did drive further from home, and there was evidence that they increased their distance travelled on primary roadways (i.e., roadways that typically have fewer conflict points and opportunities for crashes). More research on cataract surgery and driving exposure would help to elucidate the risks for crashing.

In addition to increasing their total driving distances and driving further on primary roadways, the participants also made trips that took them further from home, even though the number of trips did not change. These findings suggest that they were possibly restricting their driving less after surgery. Previous research has found that older drivers with cataracts self-report at least partly restricting their driving, and several studies have found that drivers self-report fewer difficulties with driving after cataract surgery ${ }^{1,13}$. However, we are not aware of any other studies that have objectively measured driving patterns before and after surgery.

The strengths of this study are its longitudinal nature, and the use of in-vehicle devices to objectively measure driving patterns. Because we had devices installed in participant vehicles that recorded GPS and in-vehicle information, we were able to record very detailed information about the participants' driving. Further, we were able to use that data with geographic information system (GIS) tools to characterize the location and timing of those trips. 
Limitations of the study include the small sample size, the lack of a control group, and the nonrandom sample. However, even with a small sample size, we were able to show significant changes in several variables, which indicates the large effects seen. In terms of a lack of a control group, we would expect that older drivers would drive less over time, rather than more. Candrive data on a much larger sample of participants confirm this (unpublished data). While the sample for the Candrive study was a convenience sample, it has been shown that the Candrive participants are very similar to older Canadian drivers in many ways, based on a comparison with a national random sample survey (Canadian Community Health Survey) ${ }^{15}$.

Another drawback to this study, due to the small sample size, is that we did not separate out cases based on the type of cataract surgery (first, second or both eyes). As Agramunt et al. indicate in their systematic review, there are many gaps in the literature on cataract surgery and driving ${ }^{1}$. This includes what are the effects by each type of surgery. For example, "it is also important to determine whether second eye surgery provides specific additional benefits for driving performance....”1 (pg 792). In a related field, it has been found that cataract surgery has different effects on fall prevention, depending on whether only one eye or the second eye has been done ${ }^{16}$.

In conclusion, this study provides preliminary evidence that cataract surgery results in changes in older adults' driving patterns. These changes include increased distances, trips that are further from home, and more travel on primary roads. Future naturalistic driving studies, with larger groups of older drivers who have well-defined cataract surgery of different types, could further 
examine details of driving performance under real-world conditions using video assessment, as well as exposure (location and distances driven).

\section{ACKNOWLEDGEMENTS}

Funding Source:

This study was funded by a Team Grant from the Canadian Institutes of Health Research (CIHR) entitled “The CIHR Team in Driving in Older Persons (Candrive II) Research Program” (grant 90429; www.candrive.ca).

Conflict of interest:

None

Author contributions:

Porter was responsible for all aspects of the study described in this manuscript (design, overseeing data collection, statistical analyses and writing). Cull performed the analyses of the raw data and reviewed the manuscript.

Sponsors role:

The sponsors were not involved in any aspects of the study.

The CIHR Team in Older Persons (Candrive II) includes: Dr. Shawn Marshall, Dr. Anna Byszewski, Dr. Michel Bédard, Dr. Hillel Finestone, Dr. Sylvain Gagnon, Dr. Isabelle Gélinas, 
Dr. Nicol Korner-Bitensky, Dr. Linda Li, Dr. Barbara Mazer, Dr. Jeannette Montufar, Dr. Anita Myers, Dr. Gary Naglie, Dr. Jan Polgar, Dr. Michelle Porter, Dr. Mark Rapoport, Dr. Ian Stiell, Dr. Holly Tuokko, and Dr. Brenda Vrkljan.

The Candrive Investigators thank Lynn MacLeay, Candrive Program Manager, for her role in managing and operationalizing the study for the Canadian sites. The Candrive Investigators thank the Research Associates for their dedication and contribution to the success of the study Candrive Research Coordinators; Jennifer Biggs and Anita Jessup (Ottawa Coordinating Centre).

We thank the Candrive cohort study participants for their dedication. Without their commitment, this publication would not have been possible. We would like to thank the following individuals for their work associated with the Winnipeg site of Candrive: Linda Johnson, Joanne Parsons, Glenys Smith, Satoru Nakagawa, and Sandra Webber. 


\section{REFERENCES}

1. Agramunt S, Meuleners LB, Fraser ML, Morlet N, Chow KC, Ng JQ. Bilateral cataract, crash risk, driving performance, and self-regulation practices among older drivers. $J$ Cataract Refract Surg 2016;42:788-94. DOI: 10.1016/j.jcrs.2016.02.023

2. Owsley C, McGwin G, Jr, Sloane M, Wells J, Stalvey BT, Gauthreaux S. Impact of cataract surgery on motor vehicle crash involvement by older adults. JAMA 2002;288:841-9.

3. Meuleners LB, Hendrie D, Lee AH, Ng JQ, Morlet J. The effectiveness of cataract surgery in reducing motor vehicle crashes: a whole population study using linked data. Ophthalmic Epidemiol 2012;19:23-8. DOI: 10.310909286586.2011.628776

4. Langford J, Methorst R, Hakamies-Blomqvist L. Older drivers do not have a high crash risk--a replication of low mileage bias. Accid Anal Prev 2006;38:574-8. DOI: 10.1016/j.aap.2005.12.002

5. Staplin L, Lococo K, Gish K, Decina L. Model driver screening and evaluation program final technical report, Volume 2: Maryland Pilot Older Driver Study. Washington, DC, National Highway Traffic Safety Administration. Report No. DOT HS 809 583, 2003.

6. Huebner KD, Porter MM, Marshall SC. Validation of an electronic device for measuring driving exposure. Traffic Inj Prev 2006;7:76-80. DOI: 10.1080/15389580500413067 
7. Porter MM, Smith GA, Cull AW, Myers AM, Bédard M, Gélinas I et al. Older driver estimates of driving exposure compared to in-vehicle data in the Candrive II study. Traffic Inj Prev 2015;16:24-7. DOI: 10.1080/15389588.2014.894995

8. Marshall SC, Man-Son-Hing M, Bédard M, Charlton J, Gagnon S, Gélinas I et al. Protocol for Candrive II/Ozcandrive, a multicentre prospective older driver cohort study. Accid Anal Prev 2013;61:245-52. DOI: 10.1016/j.aap.2013.02.009

9. Smith GA, Porter MM, Cull AW, Mazer B, Myers AM, Naglie G, et al. Seasonal and weather effects on older adults' driving trip distances. Can J Aging 2016;35(S1):59-68. DOI: $10.1017 / S 07149808160000040$

10. Jun J, Ogle J, Guensler R. Relationships between crash involvement and temporal-spatial driving behavior activity patterns: Use of data for vehicles with global positioning systems. Transport Res Rec 2007;2019:246-55. DOI: 10.3141/2019-29

11. Key:highway. (2015, December 16). OpenStreetMap Wiki. http://wiki.openstreetmap.org/w/index.php?title=Key:highway\&oldid=1252020 Accessed October 2, 2015.

12. MacDonald, L, Myers, AM, Blanchard, RA. Correspondence among older drivers' perceptions, abilities and behaviors. Topics Geriatr Rehab 2008;24:239-252. 
13. Monestam, E, Wachtmeister, L. Impact of cataract surgery on car driving: a population based study in Sweden. Brit J Ophthalmol 1997;81:16-22.

14. Wood, JM, Carberry, TM. Bilateral cataract surgery and driving performance. Brit J Ophthalmol 2006;90:1277-1280.

15. Gagnon, S, Marshall, SC, Kadulina, Y, Stinchcombe, A, Bédard, M, Gélinas, I et al. Assessing the Representativeness of a Convenience Sample of Older Drivers: A Comparison between the CIHR Candrive Cohort Study Sample and the Household Population of Canadians with Valid Driver's Licenses. C J Aging 2016;35(S1):99 - 109.

16. Meulener, LB, Fraser, ML, Ng, J, Morlet, N. The impact of first- and second-eye cataract surgery on injurious falls that require hospitalization: a whole population study. Age Ageing 2014;43:341-346. 
Table 1. Comparison of Selected Variables Before and After Cataract Surgery.

\begin{tabular}{|c|c|c|c|}
\hline Variable & Before & After & $p$ value \\
\hline Number of trips ${ }^{a}$ & $301.7 \pm 252.0$ & $310.4 \pm 231.6$ & 0.742 \\
\hline Total distance $(\mathrm{km})^{\mathrm{a}}$ & $1472 \pm 1221$ & $1878 \pm 1278$ & 0.022 \\
\hline Night distance ${ }^{a}$ & $312.9 \pm 360.3$ & $242.9 \pm 284.0$ & 0.242 \\
\hline Distance from home $(\mathrm{km})$, median ${ }^{\mathrm{b}}$ & $1.9 \pm 1.3$ & $2.3 \pm 1.8$ & 0.007 \\
\hline Distance from home $(\mathrm{km})$, maximum ${ }^{\text {a }}$ & $30.5 \pm 26.4$ & $66.2 \pm 49.2$ & 0.017 \\
\hline Distance on primary roads $(\mathrm{km})^{\mathrm{c}}$ & $341.5 \pm 380.4$ & $578.0 \pm 511.8$ & $<0.05$ \\
\hline Number of hard brakes per km (\#) ${ }^{b}$ & $0.069 \pm 0.036$ & $0.032 \pm 0.13$ & $<0.001$ \\
\hline Number of hard brakes per stop ${ }^{b}$ & $0.03 \pm 0.02$ & $0.03 \pm 0.03$ & 0.298 \\
\hline
\end{tabular}

Note: ${ }^{\mathrm{a}}$ paired t-test,${ }^{\mathrm{b}}$ Wilcoxon signed rank test, ${ }^{\mathrm{c}}$ Holms-Sidak post hoc test 


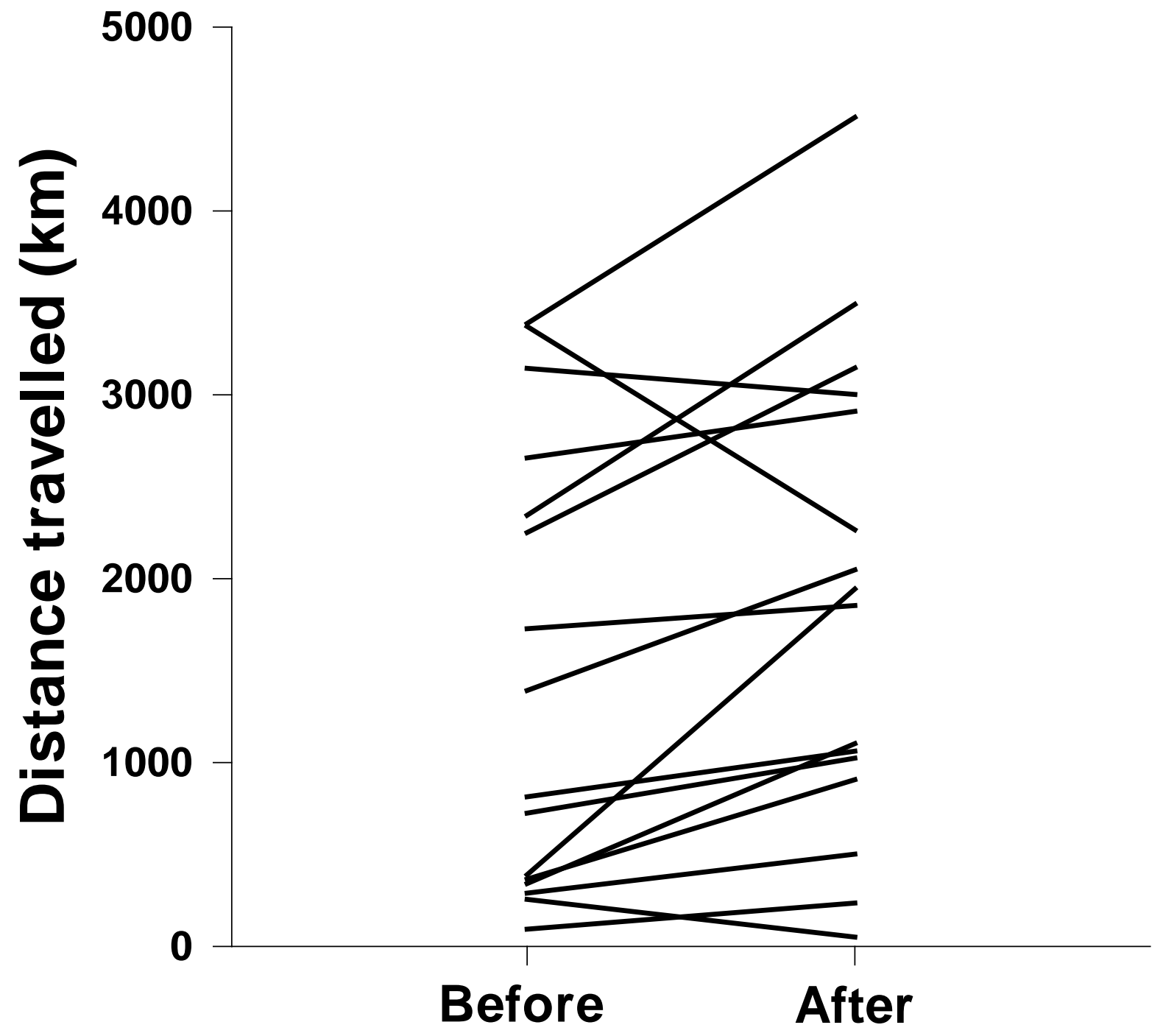

Figure 1. Individual driving distances before and after cataract surgery. 